\title{
Mindfulness training alters emotional memory recall compared to active controls: support for an emotional information processing model of mindfulness
}

\section{Douglas Roberts-Wolfe ${ }^{1,2,3}$, Matthew D. Sacchet ${ }^{1,2,4}$, Elizabeth Hastings ${ }^{1,5}$, Harold Roth ${ }^{1,6,7}$ and Willoughby Britton ${ }^{1,2}$ *}

\author{
${ }^{1}$ Contemplative Studies Initiative, Brown University, Providence, RI, USA \\ ${ }^{2}$ Department of Psychiatry and Human Behavior, Brown University Medical School, Providence, RI, USA \\ ${ }^{3}$ Medical Scientist Training Program, Medical University of South Carolina, Charleston, SC, USA \\ ${ }^{4}$ Neurosciences PhD Program, Stanford University School of Medicine, Stanford, CA, USA \\ ${ }^{5}$ Department of Cognitive, Linguistic, and Psychological Sciences, Brown University, Providence, RI, USA \\ ${ }^{6}$ Department of Religious Studies, Brown University, Providence, RI, USA \\ 7 Department of East Asian Studies, Brown University, Providence, RI, USA
}

\section{Edited by:}

Jack Van Honk, Utrecht University, Netherlands

\section{Reviewed by:}

Franco Cauda, University of Turin, Italy David Terburg, Universiteit Utrecht, Netherlands

\section{${ }^{*}$ Correspondence:}

Willoughby Britton, Department of Psychiatry and Human Behavior, Warren Alpert Medical School at Brown University, 185 Brown Street Providence, RI 02906, USA. e-mail:willoughby_britton@brown.edu

\begin{abstract}
Objectives: While mindfulness-based interventions have received widespread application in both clinical and non-clinical populations, the mechanism by which mindfulness meditation improves well-being remains elusive. One possibility is that mindfulness training alters the processing of emotional information, similar to prevailing cognitive models of depression and anxiety. The aim of this study was to investigate the effects of mindfulness training on emotional information processing (i.e., memory) biases in relation to both clinical symptomatology and well-being in comparison to active control conditions. Methods: Fifty-eight university students ( 28 female, age $=20.1 \pm 2.7$ years) participated in either a 12 -week course containing a "meditation laboratory" or an active control course with similar content or experiential practice laboratory format (music). Participants completed an emotional word recall task and self-report questionnaires of well-being and clinical symptoms before and after the 12-week course. Results: Meditators showed greater increases in positive word recall compared to controls $[F(1,56)=6.6, p=0.02]$. The meditation group increased significantly more on measures of well-being $[F(1,56)=6.6, p=0.01]$, with a marginal decrease in depression and anxiety $[F(1,56)=3.0, p=0.09]$ compared to controls. Increased positive word recall was associated with increased psychological well-being $(r=0.31, p=0.02)$ and decreased clinical symptoms $(r=-0.29, p=0.03)$. Conclusion: Mindfulness training was associated with greater improvements in processing efficiency for positively valenced stimuli than active control conditions. This change in emotional information processing was associated with improvements in psychological well-being and less depression and anxiety. These data suggest that mindfulness training may improve well-being via changes in emotional information processing. Future research with a fully randomized design will be needed to clarify the possible influence of self-selection.
\end{abstract}

Keywords: emotional information processing, mindfulness, memory

\section{INTRODUCTION}

Mindfulness-based interventions (MBI), including mindfulnessbased stress reduction (MBSR) and mindfulness-based cognitive therapy (MBCT), are accumulating growing empirical support for improvements in psychological well-being in a wide range of clinical and non-clinical populations (Baer, 2003; Grossman et al., 2004; but see also Ospina et al., 2007). MBI were originally introduced as behavioral interventions to be practiced by chronic pain patients (Kabat-Zinn, 1982) and have now been shown to positively affect clinical outcomes when practiced by clinicians (Epstein, 1999; Grepmair et al., 2007). Researchers have proposed a variety of means by which this process may produce enhancements in well-being (Bishop, 2002; Dimidjian and Linehan, 2003; Shapiro et al., 2006), but the mechanism of action remains unclear.
One possibility is that mindfulness training alters the processing of emotional information, similar to prevailing cognitive models of depression and anxiety (Beck, 1987; Hakamata et al., 2010). These models are based on observations that distressed individuals process emotional information differently than healthy, happy individuals (Beck, 1987; Hakamata et al., 2010). Distressed (depressed or anxious) individuals have attentional and memory biases toward negative stimuli and away from positive stimuli (Burt et al., 1995; Mathews and MacLeod, 2005; Kellough et al., 2008; Disner et al., 2011). Healthy individuals, in contrast, have a preferential bias toward positive stimuli (Gotlib et al., 2004; Reidy, 2004) that is associated with a wide range of adaptive qualities and greater well-being (Taylor and Brown, 1988; Scheier et al., 2001). In contrast, both the presence of negative biases and/or the 
lack of positive biases are predictive of future episodes of depression and anxiety and may play a role in causing or maintaining these disorders (Mathews and MacLeod, 2005; Disner et al., 2011). Furthermore, successful modification of cognitive biases parallels symptom improvement following cognitive behavioral therapy (Pishyar et al., 2008), pharmacotherapy (Mogg et al., 2004), or systematic training aimed at altering biases (Hakamata et al., 2010; Beard et al., 2011).

These emotional biases in both attention and memory are thought to be caused by an imbalance of top-down cortical control and a prepotency of bottom-up subcortical reactivity, or more specifically, poor prefrontal attentional control over the amygdala (Beck, 2008; Disner et al., 2011). Depressed and anxious patients show increased amygdala activity and decreased activation of the anterior cingulate cortex (ACC) and lateral prefrontal cortex (PFC) in response to negative stimuli (Browning et al., 2010; Disner et al., 2011). The amygdala is a key component in emotion processing in the brain, and is critically involved in fear conditioning and threat detection (Davis, 1992; LeDoux, 2003; Arne, 2005). The PFC is thought to play a key role in cognitive control and attentional mechanisms (Miller and Cohen, 2001; Nagahama et al., 2001), and the ACC has been implicated in cognitive control functions such as error detection (Carter et al., 1998) and attention (Weissman et al., 2005). The ACC and PFC exert inhibitory control on limbic structures such as the amygdala (Mayberg et al., 1999; Davidson et al., 2000; Ochsner et al., 2002, 2004; Ochsner and Gross, 2005; Urry et al., 2006). Lack of such inhibitory control results in a hyperactive amygdala (Siegle et al., 2002, 2007b) and an associated increase in sympathetic hyperarousal, emotional reactivity, affective disturbance (Baxter et al., 1989; Bench et al., 1993; Mayberg et al., 1999; Davidson et al., 2000; Clark et al., 2002; Siegle and Hasselmo, 2002; Siegle et al., 2002; Blumberg et al., 2004; Meyer et al., 2004) and biases in attention and memory away from positive stimuli and toward negative stimuli (Fales et al., 2008; Beevers et al., 2010; Koster et al., 2010).

Poor prefrontal control or "hypofrontality" is ubiquitous across a wide range of psychiatric conditions, including depression, anxiety, substance abuse, attention deficit disorders and schizophrenia (Clark et al., 2009; Couyoumdjian et al., 2010). Restoration of PFC functioning in these conditions parallels response to treatment in both pharmacological and behavioral interventions (Liotti and Mayberg, 2001; Liotti et al., 2002; Davidson et al., 2003a; Hugdahl et al., 2007). Because impairment of prefrontal attention circuits plays such a central role in emotional disturbance, many researchers have attempted to use deliberate attention training or cognitive "remediation" exercises to restore prefrontal functioning (Wells, 2000; Penades et al., 2006; Siegle et al., 2007a; O'Connell et al., 2008). This so-called "cognitive bias modification" (CBM) training, in which patients learn to shift attention toward positive stimuli or away from negative stimuli (Koster et al., 2009; Beard et al., 2011) represents "a focused attempt to teach patients one specific skill, attention control” (Hakamata et al., 2010). Results indicate that successful modification of cognitive biases resulted in decreased symptoms of anxiety and depression and greater well-being in clinical populations (Mathews and MacLeod, 2005; Mathews et al., 2007; Salemink et al., 2007; Beard and Amir, 2008; Li et al., 2008; Amir et al., 2009; Hazen et al., 2009; Klumpp and Amir, 2009; Schmidt et al., 2009; See et al., 2009; Sin and Lyubomirsky, 2009; Eldar and Bar-Haim, 2010; Hakamata et al., 2010). Thus, classic CBT may be moving toward the incorporation of "procedures [that] may alter cognitive biases through a more implicit, experiential process” (Beard et al., 2011).

A substantial body of research supports the use of meditationbased mental training as candidate for strengthening or rehabilitating prefrontal attentional control systems. There are several different forms and many variations of meditation training, but a central feature is the systematic training of attentional capacities (Lutz et al., 2008).

Meditation training is associated with better performance on a wide range of prefrontally mediated attention tasks (Valentine and Sweet, 1999; Wenk-Sormaz, 2005; Brefczynski-Lewis et al., 2007; Chan and Woollacott, 2007; Jha et al., 2007; Pagnoni and Cekic, 2007; Slagter et al., 2007; Srinivasan and Baijal, 2007; Tang et al., 2007; Chambers et al., 2008; Bushell, 2009; Lutz et al., 2009; Goldin and Gross, 2010), with increased activity in the (lateral) PFC (Herzog et al., 1990; Jevning et al., 1996; Khushu et al., 2000; Lazar et al., 2000; Baerentsen et al., 2001; Newberg et al., 2001; Ritskes et al., 2003; Brefczynski-Lewis et al., 2007; Creswell et al., 2007; Farb et al., 2007, 2010; Holzel et al., 2007), larger frontal gray matter volumes (Lazar et al., 2005; Pagnoni and Cekic, 2007; Hölzel et al., 2008; Luders et al., 2009), and decreased levels of negative affect, anxiety, and depression (Kabat-Zinn et al., 1992; Shapiro et al., 1998; Speca et al., 2000; Grossman et al., 2004; Allen et al., 2006; Jain et al., 2007; Kenny and Williams, 2007; Kuyken et al., 2008; Witek-Janusek et al., 2008). Meditation training is associated with greater PFC inhibition of the amygdala (Brefczynski-Lewis et al., 2007; Creswell et al., 2007; Farb et al., 2007; Goldin and Gross, 2010; Hölzel et al., 2010; Way et al., 2010), less emotional reactivity (Britton et al., in press) and decreased sympathetic hyperarousal (Sudsuang et al., 1991; MacLean et al., 1994; Carlson et al., 2007; Britton et al., 2010).

Even though Beard et al. (2011) lists mindfulness training as a CBM exercise, only a handful of studies have examined the effects of mindfulness on cognitive biases. The existing studies are also constrained by a number of methodological limitations. While two studies have found that MBCT was associated with decreased depression-related memory impairment (over-general memory, or the tendency to summarize rather than recall specific details), the target variable was memory specificity, not memory valence (Williams et al., 2000; Heeren et al., 2009), and does not address the issue of emotional biases. In a sample of fibromyalgia patients, Vago and Nakamura (2011) found that an 8 week mindfulness training was associated with altered threat-related attentional biases compared to no-treatment control (as evidenced by decreased avoidance of pain-threat words during early stages of attention in fibromyalgia patients and improved disengagement from pain-threat words during later stages of attention). Cognitive bias was only assessed post-intervention, however, and baseline differences were not assessed. In a sample of undergraduates, Alberts and Thewissen (2011) found that a 12-min breath awareness induction prior to verbal learning task resulted in decreased memory for negative words compared to a control group that received no induction. However, one-time mindfulness inductions do not necessarily generalize to longer-term mindfulness training 
(Davidson, 2010). Furthermore, mindfulness induction just prior to the task introduces the confound of state, rather than trait, effects of meditation. A standard multi-week mindfulness intervention would yield more conclusive results about trait effects of mindfulness training.

In addition to the design limitations, the control groups in the above studies did not receive any comparable intervention, and thus it cannot be concluded that the effects on cognitive bias were due to meditation practice, rather than non-specific effects of deliberate effort, expectation, group interaction or didactic content. We attempted to address this methodological limitation by comparing meditation participants to participants who also received a similar ratio of didactic to experiential body-based attention training (music) or similar didactic content but did not meditate. It should be noted that participants self-selected, and were not randomly assigned to their courses.

Another limitation of existing mindfulness and cognitive bias studies, and the cognitive bias literature in general, is the narrow focus on negative affect and psychopathology without including the full range of positive affect and well-being. The World Health Organization's (1948) definition of health is "not merely the absence of disease or infirmity" but "a state of complete physical, mental and social well-being." Mindfulness training differs from most psychotherapy in that it is sought not only for relief of suffering, but also for greater well-being and quality of life (Carmody and Baer, 2008; NCCAM, 2009; Schroevers and Brandsma, 2010), constructs that are related but functionally distinct (Ryff et al., 2006). Thus, this paper's inclusion of psychological well-being, in addition to distress, will serve to address an important outcome of mindfulness training, as well as extend the investigation of cognitive biases into the domain of well-being.

A final limitation of mindfulness research in general is the widespread reliance on self-report measures, which are subject to a wide array of biases, including memory bias (Schwarz, 1999; Baumeister et al., 2007) and treatment expectations (Howard and Dailey, 1979; Howard, 1980; Geers and Rose, 2011). Indeed, self-reports may be especially problematic in mindfulness interventions because they alter introspective ability (Davidson, 2010). Our use of an objective task to assess emotional bias is intended to introduce an alternative to self-reports.

In order to address these gaps in the literature, the present study assessed objective emotional information processing in relation to both psychological well-being and depression/anxiety before and after 12 weeks of mindfulness training or comparable didactic/experiential learning. Cognitive models predict that biases operate at all levels of processing, including attention, encoding and retrieval (Bradley et al., 1994). While research findings about emotional biases in attention have been inconsistent, more robust findings have been found at the deepest levels of processing, i.e., with biases in explicit memory recall (Baños et al., 2001). We therefore chose to use an explicit memory task as our measure of emotional information processing. We hypothesized that (1) mindfulness would improve emotional information processing (increased positive word recall and/or decreased negative word recall), (2) mindfulness training would decrease depression/anxiety and increase psychological well-being, (3) emotional information processing improvements would accompany improvements in depression/anxiety and well-being.

\section{MATERIALS AND METHODS PARTICIPANTS}

Undergraduates $(N=58,28$ female, Age $=20.10 \pm 2.67$ years, range 17-35 years) were recruited from three types of courses at Brown University (Providence, RI, USA): (a) "Meditation laboratories" or (b) Music, or (c) Religious Studies, with the understanding that the results of their training in these courses would be the subject of the current study. Meditation Labs courses consisted of lecture and practice-based learning components in mindfulness meditation. Control courses were chosen for similar course format (Music) or content (Religious/East Asian Studies). Participants were recruited in the first week of classes and completed written informed consent procedures. The study protocol was approved by the Brown University Institution Review Board. There were no exclusion criteria besides age.

\section{PROCEDURES}

Participants completed assessments at the beginning and end of a 12-week course. Assessments included self-report questionnaires and a 2-hour in-lab neuropsychological battery. The experiments were conducted between January 2008 and December 2010 on Brown University campus in Providence, RI, USA. No adverse events occurred during the course of the study.

\section{Word recall task}

Two lists of 22 words were selected from affective norms for English words (ANEW; Bradley and Lang, 1999). Each list included six positive (normative valence $=7.5 \pm 0.40$, arousal $=5.8 \pm 0.80$ ), six negative (valence $=2.6 \pm 0.73$, arousal $=5.5 \pm 1.37$ ), and six neutral words (valence $=5.18 \pm 0.34$, arousal $=3.84 \pm 0.48$ ), as well as two extra neutral "buffer" words at the beginning and end of the presentation to control for primacy and recency effects. Lists were balanced for valence, arousal, length, and frequency of appearance in the English language. Words were block randomized with no words of the same valence appearing consecutively. Words were presented on a $15^{\prime \prime}$ computer screen using DMDX software (Forster and Forster, 2003). Based on the suggestions of Koster et al. (2010) to assess multiple modalities in the same subject to confirm that the findings are not limited to any one form of processing, subjects received a visually presented list followed by an aurally presented list. The first list was presented visually in white font on a black background, the second aurally at a volume level set by participants. Subjects were asked to rate each word (19) on two dimensions, pleasantness and arousal to ensure depth of processing. Two separate sets of lists were counterbalanced for pre- and post-treatment administration. Participants were told that they "may be asked to recall these words sometime in the future," Immediately after presentation, participants were asked to recall the words in any order. There was no time limit.

\section{Self-report measures}

The mood and anxiety symptom questionnaire (MASQ; Clark and Watson, 1991) is a 90-item questionnaire assessing symptoms specific to depression (anhedonia, low positive affect) or anxiety 
(physiological hyperarousal) as well as symptoms of general distress related to both. Response options range from 1 (not at all) to 5 (extremely). The possible range of scores is $90-450$. We used the aggregate MASQ score, in which higher scores indicate greater levels of anxiety/depression. Cronbach's alpha was 0.92.

The Scales of Psychological Well-Being (SPWB; Ryff, 1989) is an 84 item questionnaire assessing psychological well-being across six domains: positive relations with others, autonomy, environmental mastery, personal growth, purpose in life, and selfacceptance. Response options range from one (strongly disagree) to six (strongly agree). The possible range of scores is from 84 to 504. We used aggregate SPWB score, in which higher scores indicate greater psychological well-being. Cronbach's alpha was 0.96 .

\section{Meditation labs}

Meditation labs were scheduled for $1 \mathrm{~h}$ three times per week and included approximately $30 \mathrm{~min}$ of a specific contemplative practice from Buddhist or Taoist traditions. The meditation laboratory was taught by the course professor and fourth author (Harold Roth), a published scholar of Buddhist and Taoist contemplative practices with over 30 years of personal practice experience in the Rinzai Zen tradition. The meditation period was followed by a 5 - to 10 -min written reflection and question-answer period. Many students also meditated outside of class, although this was optional.

Meditation training included both Samatha and Vipassana forms of practice, which included focused awareness training on a single object (like the breath) or a class of objects (like body sensations), but did not include objectless meditation (open monitoring or choiceless awareness). Meditation instruction emphasized attention allocation rather than the acceptance that is central to Western styles of mindfulness, although it incorporated ideals of letting go of evaluation.

\section{Control courses}

Music professors with comparable competence led music courses with music practice labs. These courses were structured similarly to Meditation Labs courses with comparable ratios of lecture- and practice-based learning of music. Two types of content-matched courses were included: Religious Studies or East Asian Studies courses by the same professor who led the meditation courses, and Religious Studies courses that were voted by students as being "inspirational and transformative" in content, but did not include meditation labs.

\section{STATISTICAL ANALYSES}

\section{Preliminary analyses}

All variables were examined for normality and baseline differences between groups were examined using box-and-whisker plots and $t$-tests or $\chi^{2}$ tests. Recall did not differ between visual versus aural presentation so subsequent analyses used word totals summed across both modalities.

\section{Main analyses}

The primary purpose of this study was to discover if emotional information processing (emotional word recall), clinical symptoms, and psychological well-being were differentially affected by meditation than by control classes. We first examined whether intervention-specific effects on recall depended on the valence of the words recalled using a three-way repeatedmeasures ANOVA design. Within-subjects variables of this threeway ANOVA were TIME (two levels: pre, post) and VALENCE (three levels: positive, negative, neutral). The between-subjects variable was GROUP (two levels: Meditation, Control.) We then examined intervention-specific changes separately for positive, negative, and neutral word counts using two-way repeatedmeasures ANOVAs (Group $\times$ Time). We examined effects on clinical symptoms (MASQ aggregate score) and psychological wellbeing (SPWB aggregate score) using two-way repeated-measures ANOVAs (Group $\times$ Time). Paired samples $t$-tests (pre-post) were used to determine the specific effect of each intervention for any variables with significant Group $\times$ Time interactions.

\section{Secondary analyses}

We examined the relationships among changes in cognitive bias, changes in clinical symptoms, and changes in psychological wellbeing. We calculated change scores by subtracting pre-intervention scores from post-intervention scores for each of our variables, and calculated Pearson product-moment correlation coefficients among these change scores for positive, negative, and neutral recall, and MASQ and SPWB aggregate scores.

Data were analyzed using SPSS 17.0 software (2007). Statistical significance was set at alpha levels $<0.05$, two-tailed. Results are reported as mean $\pm \mathrm{SD}$ or number/percentage unless otherwise indicated. Effect sizes were reported as partial $\eta^{2}\left(\eta_{\mathrm{p}}^{2}\right.$; small $=0.01$, medium $=0.06$, large $=0.14$; Green and Salkind, 2005).

\section{RESULTS}

\section{PRELIMINARY ANALYSES}

First, all variables were examined for normality. Box-and-whisker plots showed no outliers at pre- or post-intervention testing for any variables.

\section{Baseline characteristics}

Controls $(N=23,14$ female, Age $=19.2 \pm 0.99$ years $)$ and meditators $(N=35,14$ female, Age $=20.6 \pm 3.24)$ did not differ by age $[t(56)=1.98, p>0.05]$ or gender $\left[\chi^{2}(1, N=58)=2.42, p>0.1\right]$. Recall of visually presented words did not differ from recall of aurally presented words $[t(56)<0.2$, all $p>0.05]$. Positive word recall at pre-intervention was higher for controls than meditators $[t(56)=3.14, p=0.003]$; no other variables differed between groups at baseline. Table 1 summarizes the baseline word recall and self-report measure characteristics. As reported elsewhere (Silverstein et al., 2011), all subjects completed measures of clinical psychopathology and a 2-hour neuropsychological test battery of cognitive capacities, including memory, attention and motor speed. The clinical assessments indicated that our sample was fairly typical of a college sample, with depression and anxiety symptoms in the "mild" range. No clinically significant impairments in neuropsychological performance were noted.

\section{MAIN ANALYSIS: WORD RECALL DATA}

A significant Group $\times$ Time $\times$ Valence interaction $[F(2,55)=4.66$, $\left.p=0.011, \eta^{2}=0.15\right]$ suggested that treatment effects on word 
recall depended on word valence. A significant Group $\times$ Time interaction $\left[F(1,56)=6.61, p=0.013, \eta^{2}=0.11\right]$ for positive words indicated that changes in positive recall depended on the type of training. Meditators showed significant increases in positive word recall $[t(34)=2.39, p=0.023]$ while controls showed non-significant decreases in positive word recall $[t(22)=-1.41, p>0.1$; Figure 1). No significant main or interaction effects were found for negative, neutral, or total word recall.

\section{MAIN ANALYSIS: SELF-REPORT DATA}

\section{Psychological well-being}

Significant Group $\times$ Time interaction effects $[F(1,56)=6.62$, $\left.p=0.013, \eta^{2}=0.11\right]$ indicated that changes in SPWB scores depended on training type. Psychological well-being (SPWB total score) significantly increased in meditators $[t(34)=3.55, p=0.001]$, and non-significantly decreased in controls $[t(22)=-0.40, p>0.6$; Figure 2$)$. There were no significant main effects of Time or Group.

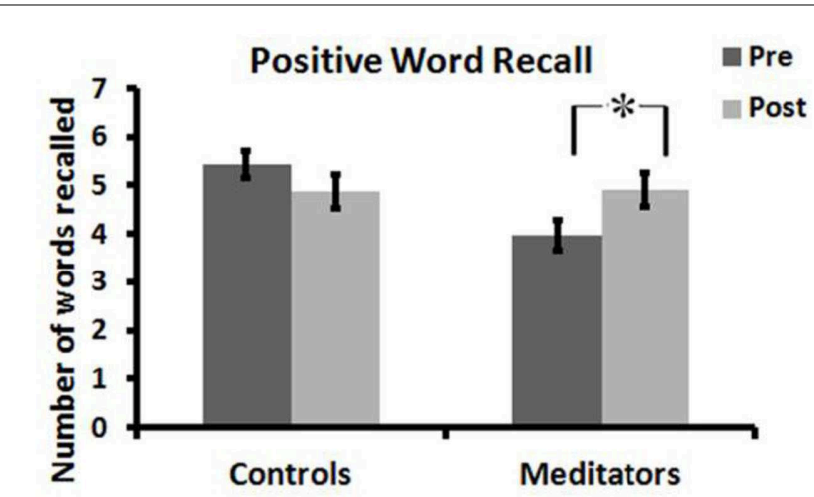

FIGURE 1 | Positive word recall before and after meditation or active control condition, ${ }^{*} \boldsymbol{p}<\mathbf{0 . 0 5}$. Error bars represent SEM.

\section{Depression/anxiety}

A trend level Group $\times$ Time interaction effect for MASQ scores $\left[F(1,56)=3.01, p=0.088, \eta^{2}=0.05\right]$ indicated that change in mood was weakly related to training type. Controls exhibited a non-significant increase in MASQ scores $[t(22)=0.142$, $p=0.17]$ while the meditators exhibited a non-significant decrease $[t(34)=-1.019, p=0.315]$. There were no significant main effects of Time or Group.

\section{SECONDARY ANALYSES: CORRELATIONS}

Pearson product-moment correlation coefficients (Table 2) were used to determine the relationships among changes in word recall and changes in clinical symptoms and psychological wellbeing. Increased positive recall was associated with increased psychological well-being $[r(56)=0.31, p=0.018$; Figure 3) and decreased clinical symptoms $[r(56)=-0.29, p=0.027$; Figure 4). Increased psychological well-being was also associated with decreased clinical symptoms $[r(56)=-0.61, p<0.001$; Figure 5).

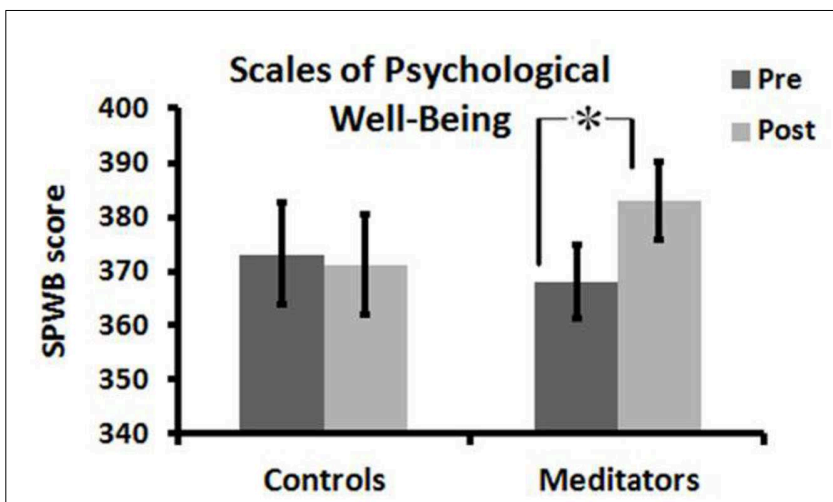

FIGURE 2 | Psychological well-being scores before and after meditation or active control condition, ${ }^{*} \boldsymbol{p}<\mathbf{0 . 0 5}$. Error bars represent SEM.

Table 1 | Mean (SD) of word recall and self-report measures before and after training in meditators and controls.

\begin{tabular}{|c|c|c|c|c|c|c|c|}
\hline & \multicolumn{2}{|c|}{ Controls $N=23$} & \multicolumn{2}{|c|}{ Meditators $N=35$} & \multicolumn{3}{|c|}{$F(1,56)$} \\
\hline & Mean & SD & Mean & SD & Time & Group & Time $\times$ group \\
\hline Baseline total words & 19.4 & 3.86 & 17.4 & 4.82 & 3.26 & 3.67 & 0.005 \\
\hline Exit total words & 20.8 & 5.27 & 18.9 & 4.90 & & & \\
\hline Baseline positive words & 5.4 & 1.41 & 4.0 & 1.92 & 0.41 & 3.2 & $6.60^{*}$ \\
\hline Exit positive words & 4.9 & 1.66 & 4.9 & 2.09 & & & \\
\hline Baseline negative words & 4.8 & 1.75 & 4.4 & 1.72 & 1.66 & 0.005 & 1.8 \\
\hline Exit negative words & 5.3 & 2.05 & 4.8 & 1.77 & & & \\
\hline Baseline neutral words & 4.6 & 1.95 & 4.6 & 2.16 & 1.09 & 1.47 & 2.65 \\
\hline Exit neutral words & 5.5 & 2.33 & 4.4 & 1.91 & & & \\
\hline Baseline MASO score & 118.7 & 17.05 & 121.3 & 23.33 & 0.19 & 0.09 & 3.01 \\
\hline Exit MASQ score & 123.9 & 19.79 & 118.1 & 23.53 & & & \\
\hline Baseline SPWB score & 373.2 & 45.84 & 368.2 & 40.53 & 3.85 & 0.1 & $6.62^{*}$ \\
\hline Exit SPWB score & 371.2 & 44.53 & 383.1 & 41.79 & & & \\
\hline
\end{tabular}

MASQ, mood and anxiety symptom questionnaire, SPWB, scales of psychological well-being. ${ }^{*} p<0.05$. 
Table 2 | Pearson product-moment correlation coefficients.

\begin{tabular}{llc}
\hline & \multicolumn{2}{c}{ Correlations $(\boldsymbol{N}=\mathbf{5 8})$} \\
\cline { 2 - 3 } & MASO change & SPWB change \\
\hline Total words change & -0.170 & 0.226 \\
Positive words change & $-0.290^{*}$ & $0.310^{*}$ \\
Negative words change & -0.037 & 0.111 \\
Neutral words change & -0.011 & 0.024 \\
MASO change & & $-0.614^{* *}$
\end{tabular}

MASQ, mood and anxiety symptom questionnaire, SPWB, scales of psychological well-being ${ }^{*} p<0.05,{ }^{*} p<0.01$.
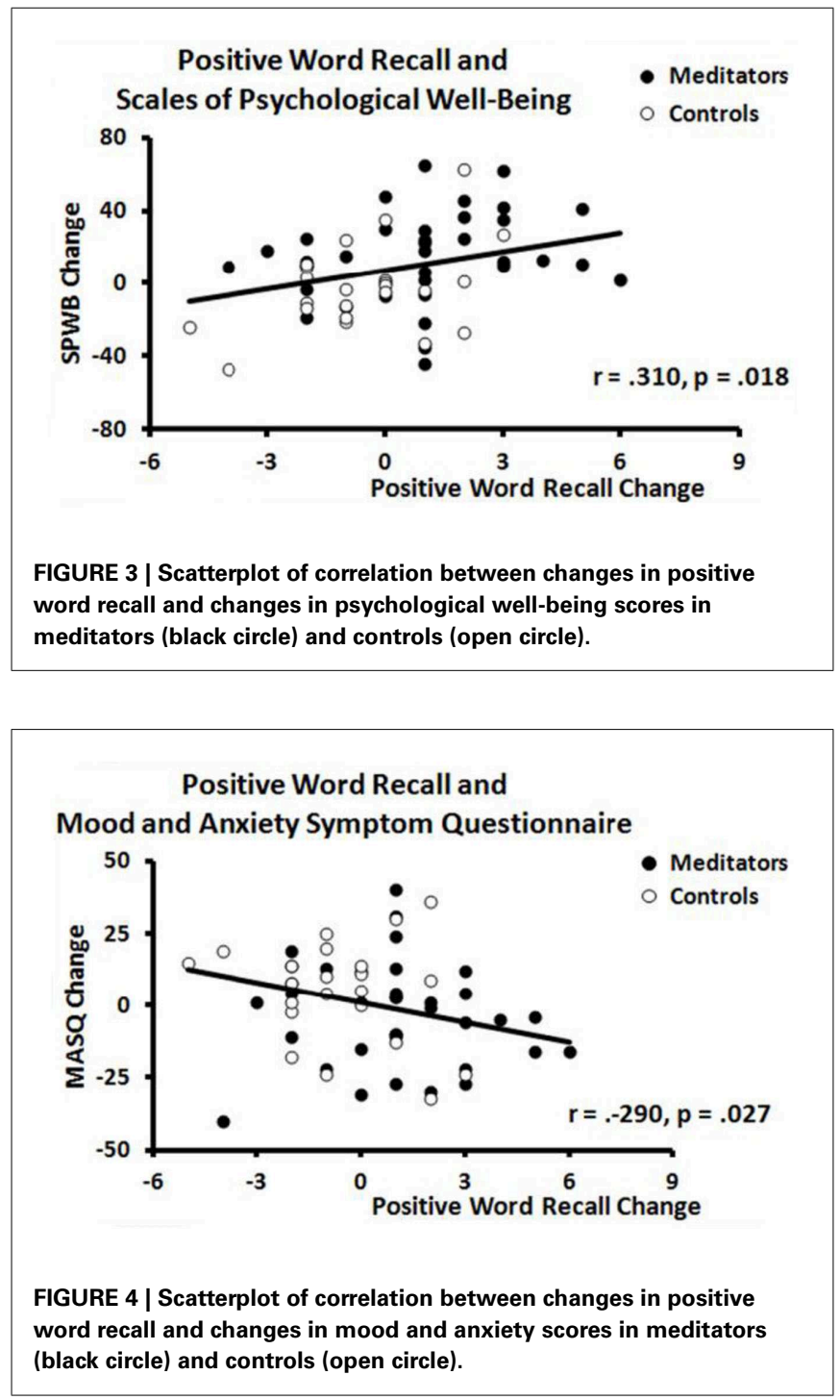

\section{DISCUSSION}

Undergraduates completed an emotional word recall task and self-report measures of anxiety/depression and well-being before and after 12 weeks of either mindfulness meditation or an active control condition. Results indicate that mindfulness training was

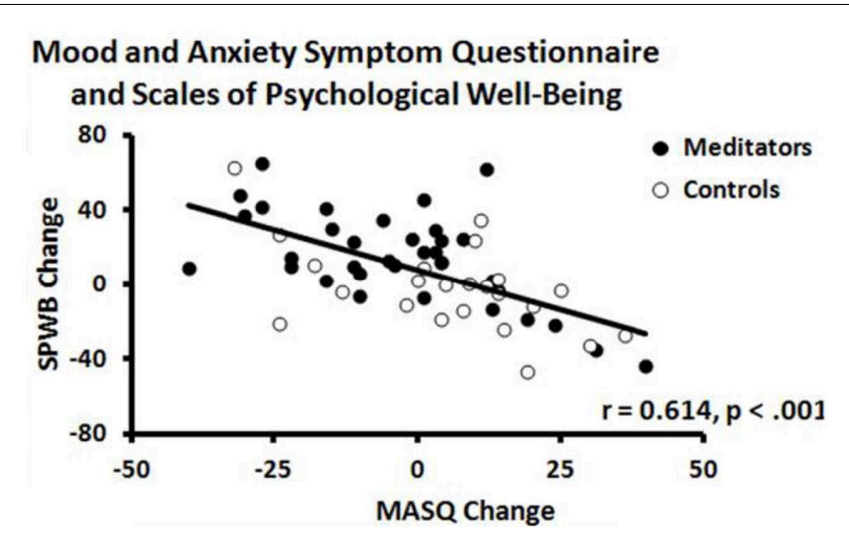

FIGURE 5 | Scatterplot of correlation between changes mood and anxiety and changes in psychological well-being scores in meditators (black circle) and controls (open circle).

associated with significantly higher increases in positive word recall and well-being than controls, and increases in positive word recall were associated with improvements in anxiety/depression and psychological well-being. Each of these findings will be discussed in detail below.

\section{MINDFULNESS TRAINING AND COGNITIVE BIAS}

The meditation participants showed significantly greater increases in positive word recall than did students in control courses. This increase in positive words occurred in the context of no change in either total word or negative word recall, which suggests an increased efficiency in positive information processing.

This pattern of findings may have a number of different explanations, as several brain areas have been associated with both meditation training and more positive/less negative memory biases. Meditation training has been associated with the neural substrates of positive affect and well-being, specifically greater activity in the left versus right PFC (Davidson et al., 2003b; Davidson, 2004; Barnhofer et al., 2010; Keune et al., 2011; Moyer et al., 2011), and increased dopaminergic tone (Kjaer et al., 2002; Burgdorf and Panksepp, 2006). The pattern of left PFC activation, which leads to greater regulation of the amygdala, coupled with dopamine, is thought to underlie a preferential tendency toward positive and rewarding stimuli (Disner et al., 2011). Neuroimaging studies have also shown that the rostral ACC is differentially activated in meditators (Lazar et al., 2000; Baerentsen et al., 2001; Holzel et al., 2007), This area is associated with trait positivity bias and optimism (Sharot et al., 2007, 2011), and dysfunction in this area is associated with deficient disengagement from negative stimuli and depression (Elliott et al., 2002; Mitterschiffthaler et al., 2008; Eugene et al., 2010).

The (right) insula, which has been found to have greater gray matter concentration (Hölzel et al., 2008, 2011) and thickness (Lazar et al., 2005) in meditators and greater activation following mindfulness training (Farb et al., 2007; Grant et al., 2010) has also been found to be associated with memory for positively valenced words (Lewis et al., 2007). The insula is thought to be involved in interoception and visceral awareness (Critchley et al., 2004), which 
are central components of mindfulness training. The meditator begins by focusing on a body-based meditation object (sensations of breathing), and re-engages body awareness as a method of disengaging from distracting thoughts. In this model, greater body awareness should be directly related with decreased distraction and greater ability to disengage attention and to redirect it according to goals. Indeed, in a study of this same sample, Silverstein et al. (2011) found greater interoceptive awareness in meditators compared to controls, and the improved body awareness was associated with decreased negative evaluative thinking, anxiety, and depression.

One proposed mechanism of depressive symptomatology reduction in mindfulness-based therapies is the reduction of overactive resting amygdala activity. Mindfulness has been associated with decreased right amygdala activity at rest and in response to negative stimuli (Way et al., 2010). In a study of expert and novice meditators, Brefczynski-Lewis et al. (2007) found a negative correlation between hours of practice and right amygdala activity. Such reductions in amygdala activity may underlie decreased facilitation of attention to negative stimuli (Disner et al., 2011; Way et al., 2010) and in turn modulate preferential recall of positively versus negatively valenced information.

Cognitive biases are partly due to difficulties in adaptively disengaging cognitive resources from negative and/or non-positive information (Fox et al., 2001; Joormann et al., 2007; Joormann and Gotlib, 2008; Gotlib and Joormann, 2010). Mindfulness facilitates adaptive disengagement of cognitive resources during the attentional blink task (Slagter et al., 2009), and may likewise facilitate adaptive disengagement of resources from emotional information that does not support emotional regulatory goals. Newly emancipated cognitive resources may then be more appropriately allocated to processing positive information in accordance with mental health goals (Josephson, 1996; Rusting and DeHart, 2000). For example, mindfulness may allow one to clear the contents of working memory in preparation for positively reappraising a distressing situation (Garland et al., 2009).

It is interesting to note that the change in emotional processing in this study was specific to positive information. Neither group showed significant changes in negative word recall, which contrasts the decrease in negative cognitive biases seen in previous mindfulness studies (Williams et al., 2000; Alberts and Thewissen, 2011; Vago and Nakamura, 2011). This absence of negative information processing changes may stem from our sample of healthy volunteers who have minimal levels of clinical distress, and by extension, negative bias. There is evidence to suggest that as one's well-being declines from a healthy, happy state, the first information processing change is the disappearance of the positive bias (Reidy, 2004), followed by the emergence of a bias toward negative information. Thus, positive information processing may be a more sensitive indicator of pre-clinical psychological disturbance than increased negative information processing (Matt et al., 1992; Hirsch and Mathews, 2000).

\section{MINDFULNESS TRAINING, PSYCHOLOGICAL WELL-BEING, AND CLINICAL SYMPTOMS}

Meditation lab participants showed a significantly greater enhancement in psychological well-being than control participants, which parallels many other studies that mindfulness training increases positive emotions (Anderson et al., 2007; Ortner et al., 2007; Nyklícek and Kuijpers, 2008; Zautra et al., 2008; Bränström et al., 2010; Schroevers and Brandsma, 2010; Geschwind et al., 2011), well-being (Shapiro et al., 1998; Ortner et al., 2007; Carmody and Baer, 2008), empathy (Shapiro et al., 1998; Krasner et al., 2009), resilience (Orzech et al., 2009), and subjective quality of life (Reibel et al., 2001; Shapiro et al., 2005; Nyklícek and Kuijpers, 2008; Fang et al., 2010), and that people are more happy when they are in a mindful state (Brown and Ryan, 2003; Killingsworth and Gilbert, 2010). Along these lines, a recent experience sampling study found that MBCT was associated with "increased experience of momentary positive emotions as well as greater appreciation of, and enhanced responsiveness to, pleasant daily life activities" (Geschwind et al., 2011), a finding that was independent of accompanying decreases in rumination, worry, and negative affect.

Mindfulness training has been hypothesized to increase wellbeing by enhancing the clarity and vividness of everyday experience (Brown and Ryan, 2003). One recent analysis of the impact of the various components of mindfulness indicated that increased attention regulation - awareness of and attention to daily experiences - are related to increased positive affect, while decreases in negative affect may be due to the development of a more accepting, open, and curious attitude to unpleasant experiences (Schroevers and Brandsma, 2010). Enhanced engagement with present-moment experiences due to meditation practice may thus broaden the scope of attention (Lutz et al., 2008) and allow greater awareness of pleasant situations.

This augmented engagement with an environment by means of enhanced attentional focus facilitates the process of "savoring," by which one becomes more consciously aware of pleasant experiences (Bryant, 1989). Savoring may serve to maintain and prolong positive emotions, thereby contributing to an upward spiral of psychological well-being (Tugade and Fredrickson, 2007), and to subjective well-being later in life (Bryant, 1989; Meehan et al., 1993).

While meditation was associated with greater well-being, the effect did not reach significance for clinical symptoms. This finding may be related to a floor effect for clinical symptoms in a nonclinical population, or a difference in sensitivity between the two instruments. Nevertheless, the pattern that mindfulness increases positive states more than it deceases negative ones is paralleled in both memory bias and self-report measures. As with cognitive bias, it makes sense that the spectrum of well-being to psychopathology also would begin with a decrease in positive states, and then progress to an increase in negative ones. Indeed, low psychological well-being has been shown to be a strong predictor of depression later in life (Wood and Joseph, 2010).

\section{CORRELATIONS AMONG EMOTIONAL INFORMATION PROCESSING, DEPRESSION/ANXIETY, AND PSYCHOLOGICAL WELL-BEING}

Increases in positive word recall were associated with increases in self-reported well-being and decreases in depression and anxiety, which indicates that biases in emotional word recall have convergent and divergent validity with self-report measures and their parallel modification with treatment. Associations have been 
found between trait positivity biases and well-being in both crosssectional and prospective studies (Taylor and Brown, 1988; Scheier et al., 2001). Other studies have found that changing attentional bias by methods such as CBM results in decreased anxiety and depression and increased well-being in clinical populations (Mathews et al., 2007; Salemink et al., 2007; Beard and Amir, 2008; Sin and Lyubomirsky, 2009).

Previous research has found that changes in cognitive biases correlate with changes in self-reported symptoms in studies of cognitive behavioral therapy (Pishyar et al., 2008) and pharmacotherapy (Mogg et al., 2004); this study extends these findings to mindfulness training. This study did not examine whether CBM mediated these improvements, and further research would be needed to establish whether cognitive bias change is a therapeutic mechanism for mindfulness-based therapies, as it appears to be for psycho- and pharmacotherapies (Harmer et al., 2003; Browning et al., 2010).

\section{CLINICAL IMPLICATIONS}

The results from this study have a number of possible implications. First, it has been hypothesized that mindfulness differs from cognitive behavioral therapy (CBT) by focusing on one's relationship to thoughts and emotions, rather than changing their content or valence (Segal et al., 2002; Beck, 2008). While the two methods may still differ in approach, these findings, as well as other findings of mindfulness-induced alterations in cognitive biases (Williams et al., 2000; Heeren et al., 2009; Alberts and Thewissen, 2011; Vago and Nakamura, 2011), suggest that the resulting alteration of emotional information processing may be similar to that seen in CBT. CBT is hypothesized to work by providing patients with repeated experiences of refocusing attention away from automatic negative schemas toward alternative views or ideas (Teasdale et al., 1995; Beck, 2008). If positive information processing is indeed a mechanism of mindfulness-based therapies, it can be more effectively incorporated into treatment (Kazdin and Nock, 2003), and future research should include CBM interventions (Bar-Haim, 2010) as active control groups.

A second implication of this study is the introduction of an easily administered, objective measure that may serve as a more viable alternative to self-reports. Our study suggests that explicit memory biases are more sensitive to change than self-reports and not as subject to demand characteristics or confounded by increased self-awareness. Indeed, objective measures of cognitive biases have been found to be better at predicting emotional and physiological reactions to stress than self-report measures (MacLeod and Hagan, 1992; van den Hout et al., 1995; Fox et al., 2010; Beard, 2011). Furthermore, differential changes in positive versus negative biases may yield more precise information about emotional information processing. For example, results from this study suggest that changes in positive emotional processing may be one of the earliest and subtlest indicators of emotional well-being or decline.

\section{STUDY LIMITATIONS AND STRENGTHS}

The study has a number of strengths that improve upon past methodology, including a longitudinal design with active controls, an objective measure of emotional information processing and the inclusion of well-being as an outcome measure in addition to distress.

The study also has a number of limitations. The healthy college sample limits the ability to generalize to a treatment-seeking clinical sample. Because participants chose their courses and were not randomized, the differences in outcome may be due in part to baseline group differences. Indeed, the meditation lab participants had significantly lower positive recall and (non-significant) lower levels of well-being and higher levels of distress than controls at baseline. The baseline differences may reflect the impact of previous training on the part of control subjects. Meditation lab participants were mostly naïve or relatively inexperienced in mindfulness, while musicians were fairly advanced, with hundreds of lifetime practice hours prior to the intervention. Music training enhances executive function (Chandrasekaran and Kraus, 2010; Kraus and Chandrasekaran, 2010), which may have resulted in more adaptive information processing biases in this group at baseline.

Alternatively, meditation lab participants may have self-selected for this course because they were experiencing emotional difficulties and hoped to attain some therapeutic benefit from the course. These baseline differences raise the possibility that the meditators' disproportionate increase in positive word recall may be a form of regression to the mean. It is also possible that the effects on recall memory and well-being of mindfulness training is only observed in people who are intrinsically motivated to do this training, and are therefore prone to placebo-effect-like confounds. However, placebo-like effects due to self-selection and expectations could also apply to students who self-selected for music courses. Given that this is the first study to measure cognitive bias both before and after a multi-week mindfulness intervention, it still represents an improvement over past studies with only one-time point (Vago and Nakamura, 2011) or brief induction procedure (Alberts and Thewissen, 2011). Future studies should employ a longitudinal design with a randomized sample to control for baseline differences.

We chose explicit memory biases because they have been more consistently documented than biases in earlier stages of processing (Mathews and MacLeod, 2005; Joormann and Gotlib, 2008). However, use of a free recall task limits the ability to disentangle if the observed effect of mindfulness on memory is due to differences in attention, encoding or retrieval of emotional information.

While our findings suggest that positive information processing may be a mechanism by which mindfulness training improves well-being, the pre-post-design could only support correlations and not a proper test of mediation. Future studies must include assessments at multiple time points, in order to establish a timeline of change that can be used to determine mediation (Kazdin and Nock, 2003) with appropriate designs and analyses (Kraemer et al., 2002, 2008; Kazdin, 2007).

\section{CONCLUSION}

Positive word recall and psychological well-being improved in parallel during a 12-week mindfulness intervention compared to active controls. These data suggest that changes in emotional information processing, specifically improved processing of positive stimuli, may be a mechanism by which mindfulness increases well-being. 


\section{ACKNOWLEDGMENTS}

Funding for this study was provided by grants T32-AT001287, MH067553-05, and K23 AT006328-01A1 from the National Institutes of Health, the Mind and Life Institute, and the Frederick Lenz and Hershey Foundations. We give special thanks to the research assistants at the Brown Contemplative

\section{REFERENCES}

Alberts, H., and Thewissen, R. (2011). The effect of a brief mindfulness intervention on memory for positively and negatively valenced stimuli. Mindfulness (N. Y.) 2, 73-77.

Allen, N. B., Chambers, R., and Knight, W. (2006). Mindfulness-based psychotherapies: a review of conceptual foundations, empirical evidence and practical considerations. Aust. N. Z. J. Psychiatry 40, 285-294.

Amir, N., Beard, C., Burns, M., and Bomyea, J. (2009). Attention modification program in individuals with generalized anxiety disorder. $J$. Abnorm. Psychol. 118, 28-33.

Anderson, N. D., Lau, M. A., Segal, Z. V., and Bishop, S. R. (2007). Mindfulness-based stress reduction and attentional control. Clin. Psychol. Psychother. 14, 449-463.

Arne, N. (2005). The role of the amygdala in human fear: automatic detection of threat. Psychoneuroendocrinology 30, 953-958.

Baer, R. A. (2003). Mindfulness training as a clinical Intervention: a conceptual and empirical review. Clin. Psychol. Sci. Pract. 10, 125-143.

Baerentsen, K. B., Hartvig, N. V., Stødkilde-Jørgensen, H., and Mammen, J. (2001). Onset of meditation explored with fMRI. Neuroimage 13, 297.

Baños, R. M., Medina, P. M., and Pascual, J. (2001). Explicit and implicit memory biases in depression and panic disorder. Behav. Res. Ther. 39, 61-74.

Bar-Haim, Y. (2010). Research review: attention bias modification (ABM): a novel treatment for anxiety disorders. J. Child Psychol. Psychiatry 51, 859-870.

Barnhofer, T., Chittka, T., Nightingale, H., Visser, C., and Crane, C. (2010). State effects of two forms of meditation on prefrontal EEG asymmetry in previously depressed individuals. Mindfulness (N Y) 1, 21-27.

Baumeister, R. F., Vohs, K. D., and Funder, D. C. (2007). Psychology as the science of self-reports and finger movements: whatever happened to actual behavior? Perspect. Psychol. Sci. 2, 396-403.

Baxter, L. R. Jr., Schwartz, J. M., Phelps, M. E., Mazziotta, J. C., Guze, B. H., Selin, C. E., Gerner, R. H., and
Sumida, R. M. (1989). Reduction of prefrontal cortex glucose metabolism common to three types of depression. Arch. Gen. Psychiatry 46, 243-250.

Beard, C. (2011). Cognitive bias modification for anxiety: current evidence and future directions. Expert Rev. Neurother. 11, 299-311.

Beard, C., and Amir, N. (2008). A multisession interpretation modification program: changes in interpretation and social anxiety symptoms. Behav. Res. Ther. 46, 1135-1141.

Beard, C., Weisberg, R. B., and Amir, N. (2011). Combined cognitive bias modification treatment for social anxiety disorder: a pilot trial. Depress. Anxiety 28, 981-988.

Beck, A. T. (1987). Cognitive models of depression. J. Cogn. Psychother. 1, 5-37.

Beck, A. T. (2008). The evolution of the cognitive model of depression and its neurobiological correlates. Am. J. Psychiatry 165, 969-977.

Beevers, C. G., Clasen, P., Stice, E., and Schnyer, D. (2010). Depression symptoms and cognitive control of emotion cues: a functional magnetic resonance imaging study. Neuroscience 167, 97-103.

Bench, C. J., Friston, K. J., Brown, R. G. Frackowiak, R. S., and Dolan, R. J. (1993). Regional cerebral blood flow in depression measured by positron emission tomography: the relationship with clinical dimensions. Psychol. Med. 23, 579-590.

Bishop, S. R. (2002). What do we really know about mindfulnessbased stress reduction? Psychosom. Med. 64, 71-83.

Blumberg, H. P., Kaufman, J., Martin, A., Charney, D. S., Krystal, J. H., and Peterson, B. S. (2004). Significance of adolescent neurodevelopment for the neural circuitry of bipolar disorder. Ann. N. Y. Acad. Sci. 1021, 376-383.

Bradley, B. P., Mogg, K., and Williams, R. (1994). Implicit and explicit memory for emotional information in non-clinical subjects. Behav. Res. Ther. 32, 65-78.

Bradley, M. M., and Lang, P. J. (1999). Affective Norms for English Words (ANEW): Stimuli, Instruction Manual and Affective Ratings. Gainesville, FL: The Center for

Studies Research Laboratory and the research participants for their time and effort. Role of Funding Source: The sponsors had no further role in study design; in the collection, analysis, and interpretation of data; in the writing of the report; and in the decision to submit the paper for publication.

Research in Psychophysiology, University of Florida.

Bränström, R., Kvillemo, P., Brandberg, Y., and Moskowitz, J. (2010). Selfreport mindfulness as a mediator of psychological well-being in a stress reduction intervention for cancer patients: a randomized study. Ann. Behav. Med. 39, 151-161.

Brefczynski-Lewis, J. A., Lutz, A., Schaefer, H. S., Levinson, D. B., and Davidson, R. J. (2007). Neural correlates of attentional expertise in long-term meditation practitioners. Proc. Natl. Acad. Sci. U.S.A. 104 11483-11488.

Britton, W. B., Bootzin, R. R., Haynes, P., and Fridel, K. W. (2010). "Polysomnographic and subjective sleep profiles before and after mindfulness-based cognitive therapy in partially remitted depression," in 8th Annual Scientific Conference for Clinicians, Researchers and Educators: Investigating and Integrating Mindfulness in Medicine, Health Care, and Society, Worcester, MA.

Britton, W. B., Shahar, B., Szepsenwol, O., and Jacobs, W. J. (in press). Mindfulness-based cognitive therapy improves emotional reactivity to social stress: results from a randomized controlled trial. Behav. Ther.

Brown, K. W., and Ryan, R. M. (2003). The benefits of being present: mindfulness and its role in psychological well-being. J. Pers. Soc. Psychol. 84, 822-848.

Browning, M., Holmes, E., and Harmer, C. (2010). The modification of attentional bias to emotional information: a review of the techniques, mechanisms, and relevance to emotional disorders. Cogn. Affect. Behav. Neurosci. 10, 8-20.

Bryant, F. B. (1989). A four-factor model of perceived control: avoiding, coping, obtaining, and savoring. J. Pers. 57, 773-797.

Burgdorf, J., and Panksepp, J. (2006) The neurobiology of positive emotions. Neurosci. Biobehav. Rev. 30, 173-187.

Burt, D. B., Zembar, M. J., and Niederehe, G. (1995). Depression and memory impairment: a metaanalysis of the association, its pattern, and specificity. Psychol. Bull. 117, 285-305
Bushell, W. C. (2009). New beginnings: evidence that the meditational regimen can lead to optimization of perception, attention, cognition, and other functions. Ann. N. Y. Acad. Sci. 1172, 348-361.

Carlson, L. E., Speca, M., Faris, P., and Patel, K. D. (2007). One year pre-post intervention follow-up of psychological, immune, endocrine and blood pressure outcomes of mindfulness-based stress reduction (MBSR) in breast and prostate cancer outpatients. Brain Behav. Immun. 21, 1038-1049.

Carmody, J., and Baer, R. (2008). Relationships between mindfulness practice and levels of mindfulness, medical and psychological symptoms and well-being in a mindfulness-based stress reduction program. J. Behav. Med. 31, 23-33.

Carter, C. S., Braver, T. S., Barch, D. M., Botvinick, M. M., Noll, D., and Cohen, J. D. (1998). Anterior cingulate cortex, error detection, and the online monitoring of performance. Science 280, 747-749.

Chambers, R., Lo, B., and Allen, N. (2008). The impact of intensive mindfulness training on attentional control, cognitive style, and affect. Cognit. Ther. Res. 32, 303-322.

Chan, D., and Woollacott, M. (2007). Effects of level of meditation experience on attentional focus: is the efficiency of executive or orientation networks improved? J. Altern. Complement. Med. 13, 651-657.

Chandrasekaran, B., and Kraus, N. (2010). Music, noise-exclusion, and learning. Music Percept. Interdiscip. J. 27, 297-306.

Clark, L., Chamberlain, S. R., and Sahakian, B. J. (2009). Neurocognitive mechanisms in depression: implications for treatment. Annu. Rev. Neurosci. 32, 57-74.

Clark, L., Iversen, S. D., and Goodwin, G. M. (2002). Sustained attention deficit in bipolar disorder. $B r$. J. Psychiatry 180, 313-319.

Clark, L. A., and Watson, D. (1991). Tripartite model of anxiety and depression: psychometric evidence and taxonomic implications. J. Abnorm. Psychol. 100, 316-336. 
Couyoumdjian, A., Sdoia, S., Tempesta, D., Curcio, G., Rastellini, E., DE Gennaro, L., and Ferrara, M. (2010). The effects of sleep and sleep deprivation on task-switching performance. J. Sleep Res. 19, 64-70.

Creswell, J. D., Way, B. M., Eisenberger, N. I., and Lieberman, M. D. (2007). Neural correlates of dispositional mindfulness during affect labeling. Psychosom. Med. 69, 560-565.

Critchley, H. D., Wiens, S., Rotshtein, P., Ohman, A., and Dolan, R. J. (2004). Neural systems supporting interoceptive awareness. Nat. Neurosci. 7, 189-195.

Davidson, R. J. (2004). Well-being and affective style: neural substrates and biobehavioural correlates. Philos. Trans. R. Soc. Lond. B Biol. Sci. 359, 1395-1411.

Davidson, R. J. (2010). Empirical explorations of mindfulness: conceptual and methodological conundrums. Emotion 10, 8-11.

Davidson, R. J., Irwin, W., Anderle, M. J., and Kalin, N. H. (2003a). The neural substrates of affective processing in depressed patients treated with venlafaxine. Am. J. Psychiatry 160, 64-75.

Davidson, R. J., Kabat-Zinn, J., Schumacher, J., Rosenkranz, M., Muller, D., Santorelli, S. F., Urbanowski, F., Harrington, A., Bonus, K., and Sheridan, J. F. (2003b). Alterations in brain and immune function produced by mindfulness meditation. Psychosom. Med. 65, 564-570.

Davidson, R. J., Jackson, D. C., and Kalin, N. H. (2000). Emotion, plasticity, context, and regulation: perspectives from affective neuroscience. Psychol. Bull. 126, 890-909.

Davis, M. (1992). The role of the amygdala in fear and anxiety. Annu. Rev. Neurosci. 15, 353-375.

Dimidjian, S., and Linehan, M. M. (2003). Defining an agenda for future research on the clinical application of mindfulness practice. Clin. Psychol. Sci. Pract. 10, 166-171.

Disner, S. G., Beevers, C. G., Haigh, E. A., and Beck, A. T. (2011). Neural mechanisms of the cognitive model of depression. Nat. Rev. Neurosci. 12, 467-477.

Eldar, S., and Bar-Haim, Y. (2010). Neural plasticity in response to attention training in anxiety. Psychol. Med. 40, 667-677.

Elliott, R., Rubinsztein, J. S., Sahakian, B. J., and Dolan, R. J. (2002). The neural basis of mood-congruent processing biases in depression. Arch. Gen. Psychiatry 59, 597-604.
Epstein, R. M. (1999). Mindful practice. JAMA 282, 833-839.

Eugene, F., Joormann, J., Cooney, R. E., Atlas, L. Y., and Gotlib, I. H. (2010). Neural correlates of inhibitory deficits in depression. Psychiatry Res. 181, 30-35.

Fales, C. L., Barch, D. M., Rundle, M. M., Mintun, M. A., Snyder, A. Z., Cohen, J. D., Mathews, J., and Sheline, Y. I. (2008). Altered emotional interference processing in affective and cognitive-control brain circuitry in major depression. Biol. Psychiatry $63,377-384$.

Fang, C. Y., Reibel, D. K., Longacre, M. L., Rosenzweig, S., Campbell, D. E., and Douglas, S. D. (2010). Enhanced psychosocial wellbeing following participation in a mindfulness-based stress reduction program is associated with increased natural killer cell activity. J. Altern. Complement. Med. 16, 531-538.

Farb, N. A., Segal, Z. V., Mayberg, H., Bean, J., Mckeon, D., Fatima, Z., and Anderson, A. K. (2007). Attending to the present: mindfulness meditation reveals distinct neural modes of selfreference. Soc. Cogn. Affect. Neurosci. 2, 313-322.

Farb, N. A. S., Anderson, A. K., Mayberg, H., Bean, J., Mckeon, D., and Segal, Z. V. (2010). Minding one's emotions: mindfulness training alters the neural expression of sadness. Emotion 10, 25-33.

Forster, K. I., and Forster, J. C. (2003). DMDX: a windows display program with millisecond accuracy. Behav. Res. Methods Instrum. Comput. 35, 116-124.

Fox, E., Cahill, S., and Zougkou, K. (2010). Preconscious processing biases predict emotional reactivity to stress. Biol. Psychiatry 67, 371-377.

Fox, E., Russo, R., Bowles, R., and Dutton, K. (2001). Do threatening stimuli draw or hold visual attention in subclinical anxiety? J. Exp. Psychol. Gen. 130, 681-700.

Garland, E., Gaylord, S., and Park, J. (2009). The role of mindfulness in positive reappraisal. Explore (NY) 5, $37-44$.

Geers, A., and Rose, J. (2011). Treatment choice and placebo expectation effects. Soc. Personal. Psychol. Compass 5, 734-750.

Geschwind, N., Peeters, F., Drukker, M., Van Os, J., and Wichers, M. (2011). Mindfulness training increases momentary positive emotions and reward experience in adults vulnerable to depression: a randomized controlled trial. J. Consult. Clin. Psychol. 79, 618-628.
Goldin, P. R., and Gross, J. J. (2010). Effects of mindfulness-based stress reduction (MBSR) on emotion regulation in social anxiety disorder. Emotion 10, 83-91.

Gotlib, I. H., and Joormann, J. (2010). Cognition and depression: current status and future directions. Annu. Rev. Clin. Psychol. 6, 285-312.

Gotlib, I. H., Krasnoperova, E., Yue, D. N., and Joormann, J. (2004). Attentional biases for negative interpersonal stimuli in clinical depression. J. Abnorm. Psychol. 113, 127-135.

Grant, J. A., Courtemanche, J. R. M., Duerden, E. G., Duncan, G. H., and Rainville, P. (2010). Cortical thickness and pain sensitivity in Zen meditators. Emotion 10, 43-53.

Green, S. B., and Salkind, N. J. (2005) Using SPSS for Windows and Macintosh: Analysing and Understanding Data. Upper Saddle River, NJ: Prentice Hall.

Grepmair, L., Mitterlehner, F., Loew, T., Bachler, E., Rother, W., Nickel, M. (2007). Promoting mindfulness in psychotherapists in training influences the treatment results of their patients: a randomized, doubleblind, controlled study. Psychother Psychosom. 76, 332-338.

Grossman, P., Niemann, L., Schmidt, S., and Walach, H. (2004) Mindfulness-based stress reduction and health benefits: a meta-analysis. J. Psychosom. Res. 57, 35-43.

Hakamata, Y., Lissek, S., Bar-Haim, Y., Britton, J. C., Fox, N. A., Leibenluft, E., Ernst, M., and Pine, D. S. (2010). Attention bias modification treatment: a meta-analysis toward the establishment of novel treatment for anxiety. Biol. Psychiatry 68, 982-990.

Harmer, C. J., Hill, S. A., Taylor, M. J., Cowen, P. J., and Goodwin, G. M. (2003). Toward a neuropsychological theory of antidepressant drug action: increase in positive emotional bias after potentiation of norepinephrine activity. Am. J. Psychiatry 160, 990-992.

Hazen, R. A., Vasey, M. W., and Schmidt, N. B. (2009). Attentional retraining: a randomized clinical trial for pathological worry. J. Psychiatr. Res. 43, 627-633.

Heeren, A., Van Broeck, N., and Philippot, P. (2009). The effects of mindfulness on executive processes and autobiographical memory specificity. Behav. Res. Ther. 47, 403-409.

Herzog, H., Lele, V. R., Kuwert, T., Langen, K. J., Rota Kops, E., and Feinendegen, L. E. (1990). Changed pattern of regional glucose metabolism during yoga meditative relaxation. Neuropsychobiology 23, 182-187.
Hirsch, C. R., and Mathews, A. (2000). Impaired positive inferential bias in social phobia. J. Abnorm. Psychol. 109, 705-712.

Hölzel, B. K., Carmody, J., Evans, K. C., Hoge, E. A., Dusek, J. A., Morgan, L., Pitman, R. K., and Lazar, S. W. (2010). Stress reduction correlates with structural changes in the amygdala. Soc. Cogn. Affect. Neurosci. 5, 11-17.

Hölzel, B. K., Carmody, J., Vangel, M., Congleton, C., Yerramsetti, S M., Gard, T., and Lazar, S. W. (2011). Mindfulness practice leads to increases in regional brain gray matter density. Psychiatry Res. 191, 36-43.

Hölzel, B. K., Ott, U., Gard, T., Hempel, H., Weygandt, M., Morgen, K., and Vaitl, D. (2008). Investigation of mindfulness meditation practitioners with voxel-based morphometry. Soc. Cogn. Affect. Neurosci. 3, 55-61.

Holzel, B. K., Ott, U., Hempel, H., Hackl, A., Wolf, K., Stark, R., and Vaitl, D. (2007). Differential engagement of anterior cingulate and adjacent medial frontal cortex in adept meditators and non-meditators. Neurosci. Lett. 421, 16-21.

Howard, G. S. (1980). Response-shift bias: a problem in evaluating interventions with pre/post self-reports. Eval. Rev. 4, 93-106.

Howard, G. S., and Dailey, P. R. (1979). Response-shift bias: a source of contamination of self-report measures. J. Appl. Psychol. 64, 144-150.

Hugdahl, K., Specht, K., Biringer, E., Weis, S., Elliott, R., Hammar, Ö., Ersland, L., and Lund, A. (2007). Increased parietal and frontal activation after remission from recurrent major depression: a repeated fMRI study. Cognit. Ther. Res. 31, 147-160.

Jain, S., Shapiro, S. L., Swanick, S. Roesch, S. C., Mills, P. J., Bell, I., and Schwartz, G. E. (2007). A randomized controlled trial of mindfulness meditation versus relaxation training: effects on distress, positive states of mind, rumination, and distraction. Ann. Behav. Med. 33, 11-21.

Jevning, R., Anand, R., Biedebach, M., and Fernando, G. (1996). Effects on regional cerebral blood flow of transcendental meditation. Physiol. Behav. 59, 399-402.

Jha, A. P., Krompinger, J., and Baime, M. J. (2007). Mindfulness training modifies subsystems of attention. Cogn. Affect. Behav. Neurosci. 7, 109-119.

Joormann, J., and Gotlib, I. H. (2008). Updating the contents of working memory in depression: interference 
from irrelevant negative material. J. Abnorm. Psychol. 117, 182-192.

Joormann, J., Yoon, K. L., and Zetsche, U. (2007). Cognitive inhibition in depression. Appl. Prev. Psychol. 12, 128-139.

Josephson, B. R. (1996). Mood regulation and memory: repairing sad moods with happy memories. Cogn. Emot. 10, 437-444.

Kabat-Zinn, J. (1982). An outpatient program in behavioral medicine for chronic pain patients based on the practice of mindfulness meditation: theoretical considerations, and preliminary results. Gen. Hosp. Psychiatry 4, 33-47.

Kabat-Zinn, J., Massion, A., Kristeller, J., Peterson, L., Fletcher, K., Pbert, L., Lenderking, W., and Santorelli, S. (1992). Effectiveness of a meditation-based stress reduction program in the treatment of anxiety disorders. Am. J. Psychiatry 149, 936-943.

Kazdin, A. E. (2007). Mediators and mechanisms of change in psychotherapy research. Annu. Rev. Clin. Psychol. 3, 1-27.

Kazdin, A. E., and Nock, M. K. (2003). Delineating mechanisms of change in child and adolescent therapy: methodological issues and research recommendations. J. Child Psychol. Psychiatry 44, 1116-1129.

Kellough, J. L., Beevers, C. G., Ellis, A. J., and Wells, T. T. (2008). Time course of selective attention in clinically depressed young adults: an eye tracking study. Behav. Res. Ther. 46, 1238-1243.

Kenny, M. A., and Williams, J. M. (2007). Treatment-resistant depressed patients show a good response to mindfulness-based Cognitive therapy. Behav. Res. Ther. 45, 617-625.

Keune, P. M., Bostanov, V., Hautzinger, M., and Kotchoubey, B. (2011). Mindfulness-based cognitive therapy (MBCT), cognitive style, and the temporal dynamics of frontal EEG alpha asymmetry in recurrently depressed patients. Biol. Psychol. 88, 243-252.

Khushu, S., Telles, S., Kumaran, S., Naveen, K. V., and Tripathi, R. P. (2000). Frontal activation during meditation based on functional magnetic resonance imaging (fMRI). Indian J. Physiol. Pharmacol. 44,34 .

Killingsworth, M. A., and Gilbert, D. T. (2010). A wandering mind is an unhappy mind. Science 330, 932-932.

Kjaer, T. W., Bertelsen, C., Piccini, P., Brooks, D., Alving, J. R., and Lou, H.
C. (2002). Increased dopamine tone during meditation-induced change of consciousness. Brain Res. Cogn. Brain Res. 13, 255-259.

Klumpp, H., and Amir, N. (2009). Examination of vigilance and disengagement of threat in social anxiety with a probe detection task. Anxiety Stress Coping 22, 283-296.

Koster, E. H. W., De Raedt, R., Leyman, L., and De Lissnyder, E. (2010). Mood-congruent attention and memory bias in dysphoria: exploring the coherence among information-processing biases. Behav. Res. Ther. 48, 219-225.

Koster, E. H. W., Fox, E., and Macleod, C. (2009). Introduction to the special section on cognitive bias modification in emotional disorders. $J$. Abnorm. Psychol. 118, 1-4.

Kraemer, H., Kiernan, M., Essex, M., and Kupfer, D. J. (2008). How and why criteria defining moderators and mediators differ between the Baron \& Kenny and MacArthur approaches. Health Psychol. 27, S101-S108.

Kraemer, H. C., Wilson, G. T., Fairburn, C. G., and Agras, W. S. (2002). Mediators and moderators of treatment effects in randomized clinical trials. Arch. Gen. Psychiatry 59, 877-883.

Krasner, M. S., Epstein, R. M., Beckman, H., Suchman, A. L., Chapman, B., Mooney, C. J., and Quill, T. E. (2009). Association of an educational program in mindful communication with burnout, empathy, and attitudes among primary care physicians. JAMA 302, 1284-1293.

Kraus, N., and Chandrasekaran, B. (2010). Music training for the development of auditory skills. Nat. Rev. Neurosci. 11, 599-605.

Kuyken, W., Byford, S., Taylor, R. S., Watkins, E., Holden, E., White, K., Barrett, B., Byng, R., Evans, A., Mullan, E., and Teasdale, J. D. (2008). Mindfulness-based cognitive therapy to prevent relapse in recurrent depression. J. Consult. Clin. Psychol. 76, 966-978.

Lazar, S. W., Bush, G., Gollub, R. L., Fricchione, G. L., Khalsa, G., and Benson, H. (2000). Functional brain mapping of the relaxation response and meditation. Neuroreport 11, 1581-1585.

Lazar, S. W., Kerr, C. E., Wasserman, R. H., Gray, J. R., Greve, D. N., Treadway, M. T., Mcgarvey, M., Quinn, B. T., Dusek, J. A., Benson, H., Rauch, S. L., Moore, C. I., and Fischl, B. (2005). Meditation experience is associated with increased cortical thickness. Neuroreport 16, 1893-1897.
LeDoux, J. (2003). The emotional brain, fear, and the amygdala. Cell. Mol. Neurobiol. 23, 727-738.

Lewis, P. A., Critchley, H. D., Rotshtein, P., and Dolan, R. J. (2007). Neural correlates of processing valence and arousal in affective words. Cereb. Cortex 17, 742-748.

Li, S., Tan, J., Qian, M., and Liu, X. (2008). Continual training of attentional bias in social anxiety. Behav. Res. Ther. 46, 905-912.

Liotti, M., and Mayberg, H. S. (2001). The role of functional neuroimaging in the neuropsychology of depression. J. Clin. Exp. Neuropsychol. 23, 121-136.

Liotti, M., Mayberg, H. S., Mcginnis, S., Brannan, S. L., and Jerabek, P. (2002). Unmasking disease-specific cerebral blood flow abnormalities: mood challenge in patients with remitted unipolar depression. Am. J. Psychiatry 159, 1830-1840.

Luders, E., Toga, A. W., Lepore, N., and Gaser, C. (2009). The underlying anatomical correlates of long-term meditation: larger hippocampal and frontal volumes of gray matter. $\mathrm{Neu}$ roimage 45, 672-678.

Lutz, A., Slagter, H. A., Dunne, J. D., and Davidson, R. J. (2008). Attention regulation and monitoring in meditation. Trends Cogn. Sci. (Regul. Ed.) 12, 163-169.

Lutz, A., Slagter, H. A., Rawlings, N. B., Francis, A. D., Greischar, L. L., and Davidson, R. J. (2009). Mental training enhances attentional stability: neural and behavioral evidence. J. Neurosci. 29, 13418-13427.

MacLean, C. R., Walton, K. G., Wenneberg, S. R., Levitsky, D. K., Mandarino, J. V., Waziri, R., and Schneider, R. H. (1994). Altered responses of cortisol, GH, TSH and testosterone to acute stress after four months' practice of transcendental meditation (TM). Ann. N. Y. Acad. Sci. 746, 381-384.

MacLeod, C., and Hagan, R. (1992). Individual differences in the selective processing of threatening information, and emotional responses to a stressful life event. Behav. Res. Ther. 30, 151-161.

Mathews, A., and MacLeod, C. (2005). Cognitive vulnerability to emotional disorders. Annu. Rev. Clin. Psychol. 1, 167-195.

Mathews, A., Ridgeway, V., Cook, E., and Yiend, J. (2007). Inducing a benign interpretational bias reduces trait anxiety. J. Behav. Ther. Exp. Psychiatry 38, 225-236.

Matt, G. E., Vázquez, C., and Campbell, W. K. (1992). Mood-congruent recall of affectively toned stimuli: a meta-analytic review. Clin. Psychol. Rev. 12, 227-255.

Mayberg, H. S., Liotti, M., Brannan, S. K., Mcginnis, S., Mahurin, R. K., Jerabek, P. A., Silva, J. A. Tekell, J. L., Martin, C. C., Lancaster, J. L., and Fox, P. T. (1999). Reciprocal limbic-cortical function and negative mood: converging PET findings in depression and normal sadness. Am. J. Psychiatry 156, 675-682.

Meehan, M. P., Durlak, J. A., and Bryant, F. B. (1993). The relationship of social support to perceived control and subjective mental health in adolescents. J. Community Psychol. 21, 49-55.

Meyer, S. E., Carlson, G. A., Wiggs, E. A., Martinez, P. E., Ronsaville, D. S., Klimes-Dougan, B., Gold, P. W., and Radke-Yarrow, M. (2004). A prospective study of the association among impaired executive functioning, childhood attentional problems, and the development of bipolar disorder. Dev. Psychopathol. 16, 461-476.

Miller, E. K., and Cohen, J. D. (2001). An integrative theory of prefrontal cortex function. Annu. Rev. Neurosci. 24 167-202.

Mitterschiffthaler, M. T., Williams, S. C., Walsh, N. D., Cleare, A. J., Donaldson, C., Scott, J., and Fu, C. H. (2008). Neural basis of the emotional stroop interference effect in major depression. Psychol. Med. 38, 247-256.

Mogg, K., Baldwin, D. S., Brodrick, P., and Bradley, B. P. (2004). Effect of short-term SSRI treatment on cognitive bias in generalised anxiety disorder. Psychopharmacology (Berl.) 176, 466-470.

Moyer, C. A., Donnelly, M. P. W., Anderson, J. C., Valek, K. C., Huckaby, S. J., Wiederholt, D. A., Doty, R. L., Rehlinger, A. S., and Rice, B. L. (2011). Frontal electroencephalographic asymmetry associated with positive emotion is produced by very brief meditation training. Psychol. Sci. 22, 1277-1279.

Nagahama, Y., Okada, T., Katsumi, Y., Hayashi, T., Yamauchi, H., Oyanagi, C., Konishi, J., Fukuyama, H., and Shibasaki, H. (2001). Dissociable mechanisms of attentional control within the human prefrontal cortex. Cereb. Cortex 11, 85-92.

NCCAM. (2009). Meditation: An Introduction. Uses of Meditation in the United States. Available at: http:// nccam.nih.gov/health/meditation/ overview.htm\#meditation.

Newberg, A., Alavi, A., Baime, M., Pourdehnad, M., Santanna, J., and 
D'Aquili, E. (2001). The measurement of regional cerebral blood flow during the complex cognitive task of meditation: a preliminary SPECT study. Psychiatry Res. 106, 113-122.

Nyklícek, I., and Kuijpers, K. (2008). Effects of mindfulness-based stress reduction intervention on psychological well-being and quality of life: is increased mindfulness indeed the mechanism? Ann. Behav. Med. 35, 331-340.

Ochsner, K. N., Bunge, S. A., Gross, J. J., and Gabrieli, J. D. E. (2002). Rethinking feelings: an fMRI study of the cognitive regulation of emotion. J. Cogn. Neurosci. 14, 1215-1229.

Ochsner, K. N., and Gross, J. J. (2005). The cognitive control of emotion. Trends Cogn. Sci. (Regul. Ed.) 9, 242-249.

Ochsner, K. N., Knierim, K., Ludlow, D. H., Hanelin, J., Ramachandran, T., Glover, G., and Mackey, S. C. (2004). Reflecting upon feelings: an fMRI study of neural systems supporting the attribution of emotion to self and other. J. Cogn. Neurosci. $16,1746-1772$.

O'Connell, R. G., Bellgrove, M. A., Dockree, P. M., Lau, A., Fitzgerald, M., and Robertson, I. H. (2008). Selfalert training: volitional modulation of autonomic arousal improves sustained attention. Neuropsychologia 46, 1379-1390.

Ortner, C., Kilner, S., and Zelazo, P. (2007). Mindfulness meditation and reduced emotional interference on a cognitive task. Motiv. Emot. 31, 271-283.

Orzech, K. M., Shapiro, S. L., Brown, K. W., and Mckay, M. (2009). Intensive mindfulness training-related changes in cognitive and emotional experience. J. Posit. Psychol. 4, 212-222.

Ospina, M. B., Bond, K., Karkhaneh, M., Tjosvold, L., Vandermeer, B., Liang, Y., Bialy, L., Hooton, N., Buscemi, N., Dryden, D. M., and Klassen, T. P (2007). Meditation practices for health: state of the research. Evid. Rep. Technol. Assess. (Full Rep.) 155, 1-263.

Pagnoni, G., and Cekic, M. (2007). Age effects on gray matter volume and attentional performance in Zen meditation. Neurobiol. Aging 28, 1623-1627.

Penades, R., Catalan, R., Salamero, M., Boget, T., Puig, O., Guarch, J., and Gasto, C. (2006). Cognitive remediation therapy for outpatients with chronic schizophrenia: a controlled and randomized study. Schizophr. Res. 87, 323-331.
Pishyar, R., Harris, L. M., and Menzies, R. G. (2008). Responsiveness of measures of attentional bias to clinical change in social phobia. Cogn. Emot. 22, 1209-1227.

Reibel, D. K., Greeson, J. M., Brainard, G. C., and Rosenzweig, S. (2001). Mindfulness-based stress reduction and health-related quality of life in a heterogeneous patient population. Gen. Hosp. Psychiatry 23, 183-192.

Reidy, J. (2004). Trait anxiety, trait depression, worry, and memory. Behav. Res. Ther. 42, 937-948.

Ritskes, R., Ritskes-Hoitinga, M., Stødkilde-Jørgensen, H., Baerentsen, K. B., and Hartman, T. (2003). MRI scanning during Zen meditation: the picture of enlightenment. Constuctivism Hum. Sci. 8, 85-89.

Rusting, C. L., and DeHart, T. (2000). Retrieving positive memories to regulate negative mood: consequences for mood-congruent memory. J. Pers. Soc. Psychol. 78, 737-752.

Ryff, C. D. (1989). Happiness is everything, or is it? Explorations on the meaning of psychological wellbeing. J. Pers. Soc. Psychol. 57, 1069-1081.

Ryff, C. D., Dienberg Love, G., Urry, H. L., Muller, D., Rosenkranz, M. A., Friedman, E. M., Davidson, R. J., and Singer, B. (2006). Psychological wellbeing and ill-being: do they have distinct or mirrored biological correlates? Psychother. Psychosom. 75, 85-95.

Salemink, E., Van Den Hout, M., and Kindt, M. (2007). Trained interpretive bias and anxiety. Behav. Res. Ther. 45, 329-340.

Scheier, M. F., Carver, C. S., and Bridges, M. W. (2001). "Optimism, pessimism, and psychological well-being," in Optimism o Pessimism: Implications for Theory, Research, and Practice (Washington, DC: American Psychological Association), 189-216.

Schmidt, N. B., Richey, J. A., Buckner, J. D., and Timpano, K. R. (2009). Attention training for generalized social anxiety disorder. J. Abnorm. Psychol. 118, 5-14.

Schroevers, M. J., and Brandsma, R. (2010). Is learning mindfulness associated with improved affect after mindfulness-based cognitive therapy? Br. J. Psychol. 101, 95-107.

Schwarz, N. (1999). Self-reports: how the questions shape the answers. Am. Psychol. 54, 93-105.

See, J., Macleod, C., and Bridle, R. (2009). The reduction of anxiety vulnerability through the modification of attentional bias: a realworld study using a home-based cognitive bias modification procedure. J. Abnorm. Psychol. 118, 65-75.

Segal, Z. V., Williams, J. M. G., and Teasdale, J. D. (2002). Mindfulness-Based Cognitive Therapy for Depression: A New Approach to Preventing Relapse. New York: Guilford Press.

Shapiro, S. L., Astin, J. A., Bishop S. R., and Cordova, M. (2005) Mindfulness-based stress reduction for health care professionals: results from a randomized trial. Int. J. Stress Manag. 12, 164-176.

Shapiro, S. L., Carlson, L. E., Astin, J. A., and Freedman, B. (2006). Mechanisms of mindfulness. J. Clin. Psychol. 62, 373-386.

Shapiro, S. L., Schwartz, G. E., and Bonner, G. (1998). Effects of Mindfulness-based stress reduction on medical and premedical students. J. Behav. Med. 21, 581-599.

Sharot, T., Korn, C. W., and Dolan, R. J. (2011). How unrealistic optimism is maintained in the face of reality. Nat. Neurosci. 14, 1475-1479.

Sharot, T., Riccardi, A. M., Raio, C. M., and Phelps, E. A. (2007). Neural mechanisms mediating optimism bias. Nature 450, 102-105.

Siegle, G., Ghinassi, F., and Thase, M. (2007a). Neurobehavioral therapies in the 21st century: summary of an emerging field and an extended example of cognitive control training for depression. Cognit. Ther. Res. 31, 235-262.

Siegle, G. J., Thompson, W., Carter, C. S., Steinhauer, S. R., and Thase, M. E. (2007b). Increased amygdala and decreased dorsolateral prefrontal BOLD responses in unipolar depression: related and independent features. Biol. Psychiatry 61, 198-209.

Siegle, G. J., and Hasselmo, M. E. (2002). Using connectionist models to guide assessment of psychological disorder. Psychol. Assess. 14, 263-278.

Siegle, G. J., Steinhauer, S. R., Thase, M. E., Stenger, V. A., and Carter, C. S. (2002). Can't shake that feeling: event-related fMRI assessment of sustained amygdala activity in response to emotional information in depressed individuals. Biol. Psychiatry 51, 693-707.

Silverstein, R., Brown, A., Roth, H., and Britton, W. B. (2011). Mindfulness training improves interoceptive awareness to sexual stimuli: implications for healthy female sexual functioning. Psychosom. Med. 73, 817-825.
Sin, N. L., and Lyubomirsky, S. (2009). Enhancing well-being and alleviating depressive symptoms with positive psychology interventions: a practice-friendly meta-analysis. $J$. Clin. Psychol. 65, 467-487.

Slagter, H. A., Lutz, A., Greischar, L. L., Francis, A. D., Nieuwenhuis, S., Davis, J. M., and Davidson, R. J. (2007). Mental training affects distribution of limited brain resources. PLoS Biol. 5, el38. doi:10.1371/journal.pbio.0050138

Slagter, H. A., Lutz, A., Greischar, L. L., Nieuwenhuis, S., and Davidson, R. J. (2009). Theta phase synchrony and conscious target perception: impact of intensive mental training. J. Cogn. Neurosci. 21, 1536-1549.

Speca, M., Carlson, L. E., Goodey, E., and Angen, M. (2000). A randomized, wait-list controlled clinical trial: the effect of a mindfulness meditation-based stress reduction program on mood and symptoms of stress in cancer outpatients. Psychosom. Med. 62, 613-622.

Srinivasan, N., and Baijal, S. (2007). Concentrative meditation enhances preattentive processing: a mismatch negativity study. Neuroreport 18 , 1709-1712.

Sudsuang, R., Chentanez, V., and Veluvan, K. (1991). Effect of Buddhist meditation on serum cortisol and total protein levels, blood pressure, pulse rate, lung volume and reaction time. Physiol. Behav. 50, 543-548.

Tang, Y. Y., Ma, Y., Wang, J., Fan, Y., Feng, S., Lu, Q., Yu, Q., Sui, D., Rothbart, M. K., Fan, M., and Posner, M. I. (2007). Short-term meditation training improves attention and self-regulation. Proc. Natl. Acad. Sci. U.S.A. 104, 17152-17156,

Taylor, S. E., and Brown, J. D. (1988). Illusion and well-being a social psychological perspective on mental-health. Psychol. Bull. 103 , 193-210.

Teasdale, J. D., Segal, Z., and Williams, J. M. G. (1995). How does cognitive therapy prevent depressive relapse and why should attentional control (mindfulness) training help? Behav. Res. Ther. 33, 25-39.

Tugade, M., and Fredrickson, B. (2007). Regulation of positive emotions: emotion regulation strategies that promote resilience. J. Happiness Stud. 8, 311-333.

Urry, H. L., Van Reekum, C. M., Johnstone, T., Kalin, N. H., Thurow, M. E., Schaefer, H. S., Jackson, C. A., Frye, C. J., Greischar, L. L., Alexander, A. L., and Davidson, R. J. (2006). Amygdala and ventromedial prefrontal cortex are inversely 
coupled during regulation of negative affect and predict the diurnal pattern of cortisol secretion among older adults. J. Neurosci. 26, 4415-4425.

Vago, D., and Nakamura, Y. (2011). Selective attentional bias towards pain-related threat in fibromyalgia: preliminary evidence for effects of mindfulness meditation training. Cognit. Ther. Res. $1-14$.

Valentine, E. R., and Sweet, P. L. G. (1999). Meditation and attention: a comparison of the effects of concentrative and mindfulness meditation on sustained attention. Ment. Health Religion Cult. 2, 59-70.

van den Hout, M., Tenney, N., Huygens, K., Merckelbach, H., and Kindt, M. (1995). Responding to subliminal threat cues is related to trait anxiety and emotional vulnerability: a successful replication of Macleod and Hagan (1992). Behav. Res. Ther. 33, 451-454.

Way, B., Creswell, J. D., Eisenberger, N. I., and Lieberman, M. D. (2010). Dispositional mindfulness and depressive symptomatology: correlations with limbic and selfreferential neural activity at rest. Emotion 10, 12-24.

Weissman, D. H., Gopalakrishnan, A., Hazlett, C. J., and Woldorff, M. G. (2005). Dorsal anterior cingulate cortex resolves conflict from distracting stimuli by boosting attention toward relevant events. Cereb. Cortex 15, 229-237.

Wells, A. (2000). Emotional Disorders and Metacognition: Innovative Cognitive Therapy. New York: Wiley.

Wenk-Sormaz, H. (2005). Meditation can reduce habitual responding. Altern. Ther. Health Med. 11, $42-58$.

Williams, J. M. G., Teasdale, J. D., Segal, Z. V., and Soulsby, J. (2000). Mindfulness-based cognitive therapy reduces overgeneral autobiographical memory in formerly depressed patients. J. Abnorm. Psychol. 109, 150-155.

Witek-Janusek, L., Albuquerque, K., Chroniak, K. R., Chroniak, C.,
Durazo-Arvizu, R., and Mathews, H. L. (2008). Effect of mindfulness based stress reduction on immune function, quality of life and coping in women newly diagnosed with early stage breast cancer. Brain Behav. Immun. 22, 969-981.

Wood, A. M., and Joseph, S. (2010). The absence of positive psychological (eudemonic) well-being as a risk factor for depression: a ten year cohort study. J. Affect. Disord. 122, 213-217.

World Health Organization. (1948). Preamble to the Constitution of the World Health Organization as Adopted by the International Health Conference, New York.

Zautra, A. J., Davis, M. C., Reich, J. W., Nicassario, P., Tennen, H., Finan, P., Kratz, A., Parrish, B., and Irwin, M. R. (2008). Comparison of cognitive behavioral and mindfulness meditation interventions on adaptation to rheumatoid arthritis for patients with and without history of recurrent depression. J. Consult. Clin. Psychol. 76, 408-421.
Conflict of Interest Statement: The authors declare that the research was conducted in the absence of any commercial or financial relationships that could be construed as a potential conflict of interest.

Received: 28 October 2011; accepted: 14 January 2012; published online: $13 \mathrm{Feb}$ ruary 2012.

Citation: Roberts-Wolfe D, Sacchet MD, Hastings E, Roth $H$ and Britton $W$ (2012) Mindfulness training alters emotional memory recall compared to active controls: support for an emotional information processing model of mindfulness. Front. Hum. Neurosci. 6:15. doi 10.3389/fnhum.2012.00015

This article was submitted to Frontiers in Emotion Science, a specialty of Frontiers in Human Neuroscience.

Copyright () 2012 Roberts-Wolfe, Sacchet, Hastings, Roth and Britton. This is an open-access article distributed under the terms of the Creative Commons Attribution Non Commercial License, which permits non-commercial use, distribution, and reproduction in other forums, provided the original authors and source are credited. 